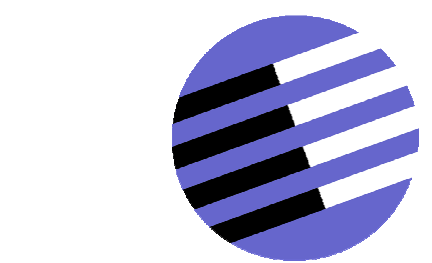

GOVERNANCE AND THE EFFICIENCY

OF ECONOMIC SYSTEMS

G E S Y

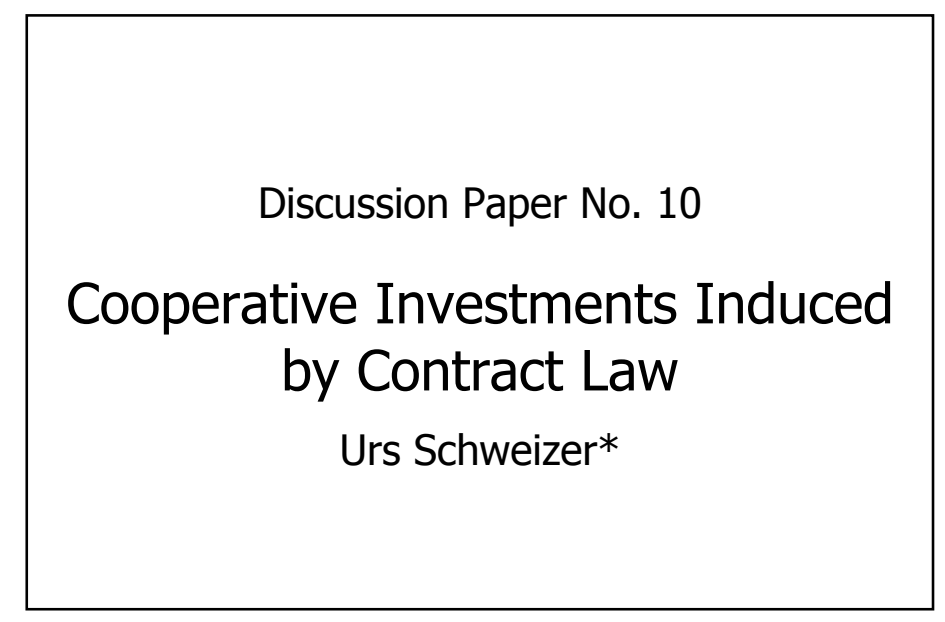

June 2004

*Urs Schweizer, Department of Economics, University of Bonn, Adenauerallee 24, D-53113 Bonn, Germany

Financial support from the Deutsche Forschungsgemeinschaft through SFB/TR 15 is gratefully acknowledged.

Sonderforschungsbereich/Transregio $15 \cdot$ www.gesy.uni-mannheim.de

Universität Mannheim . Freie Universität Berlin . Humboldt-Universität zu Berlin · Ludwig-Maximilians-Universität München Rheinische Friedrich-Wilhelms-Universität Bonn · Zentrum für Europäische Wirtschaftsforschung Mannheim 


\title{
Cooperative Investments Induced by Contract Law
}

\author{
Urs Schweizer* \\ Department of Economics \\ University of Bonn \\ Adenauerallee 24 \\ D-53113 Bonn \\ Germany \\ schweizer@uni-bonn.de
}

June 8, 2004

\begin{abstract}
This paper revisits the economic analysis of contract law for a setting of cooperative investments. While Che and Chung (1999) have shown that expectation damages perform rather poorly, the present paper argues that this negative result follows from their impicit assumption of unilateral expectation damages. Yet, the very nature of cooperative investments gives rise to the possibility that both parties may claim expectation damages. It is shown that such a regime of bilateral expectation damages provides the incentives for the first best solution even in a framework of binary choice where, for selfish investments, the traditional overreliance result would hold.

JEL classification: K12, D62
\end{abstract}

*The author wants to thank two referees as well as the editor in charge of this paper for helpful comments. All remaining errors are of course mine. 


\section{Introduction}

In a setting of relationship-specific investments, Che and Chung (1999) have explored various breach remedies for investments that generate direct benefits to the investing party's trading partner. Such cooperative investments as they are called are important for buyer-supplier alliances in industrial purchasing. Che and Chung mention investments by a supplier that increase the quality of a good or service procured by the buyer, efforts to customize components to the special needs of manufacturers and workers' paying attention to their jobs as examples of cooperative investments. Their main findings are that expectation damages perform very poorly, privately stipulated liquidated damages generate better but still inefficient incentives to invest and reliance damages perform the best.

These results stand in contrast to the earlier findings of the literature which has mainly dealt with selfish investments. Examples of such investments include situations where a supplier invests to lower his production costs or reliances of a buyer who expects the supplier to perform. Edlin and Reichelstein (1996) show that, for selfish investments and in a setting of continuous quantity choice, expectation damages may well generate efficient incentives to invest. Shavell (1980) considers selfish investments followed by a binary choice. He shows that expectation damages lead to overreliance but less so than reliance damages. Rogerson (1984) extends Shavell's analysis to the case where ex post negotiations always occur successfully and costlessly. Expectation damages still outperform reliance damages if, at the investment stage, the parties anticipate renegotiations.

The present paper revisits cooperative investments. While German contract law serves as background, other legal systems seem very similar with respect to what matters for the present analysis. In principle, the promisee is entitled to specific performance. But, for practical purposes, a substantial part of all cases are governed by expectation damages. ${ }^{1}$ The promisee, instead of expectation damages, can also claim reliance damages. ${ }^{2}$ Since disputes typically arise ex post, a rational promisee will do so only if reliance

\footnotetext{
${ }^{1}$ See $\S \S 280,283$ BGB where BGB (Bürgerliches Gesetzbuch) refers to the German Civil Code of 2 January 2002.

${ }^{2}$ See BGB $\S 284$.
} 
damages exceed expectation damages at that stage. Therefore, at least under German contract law, the question of whether reliance damages outperform expectation damages is of lesser concern. If the promisee does not claim reliance damages he will be granted expectation damages, no matter which of the two perform better. As a matter of fact, in a setting such as the one studied by Che and Chung, reliance damages would give the promisee zero net profits while, under expectation damages, he would end up, in monetary terms, as if the promisor had performed. Given that the promisee has accepted the contract initially, his net profit under performance will typically be positive. Therefore the promisee, in case of breach, would claim expectation and not reliance damages.

Does this mean that (German) contract law is not well designed to handle incomplete contracts among parties facing a situation of cooperative investments? The present paper defends contract law on this account. It argues that, in the case of cooperative investments, both parties are promisors and promisees at the same time. In fact, think of party A as a buyer who invests into the technology of party B as the seller. High investments would lead to low production costs for the seller. The (incomplete) contract stipulates a level of investments of $\mathrm{A}$ and a quantity to be delivered by $\mathrm{B}$ at some later stage as well as a net transfer price for the overall transaction. If $\mathrm{B}$ refuses to deliver A may claim compensation. But B may also claim damages if A has underinvested relative to the level specified in the contract. I shall refer to this regime as bilateral expectation damages. The main findings of the present paper are that, no matter whether renegotiations can be ruled out or not, bilateral expectation damages perform very well in cases of cooperative investments. In fact, even the first best can be achieved.

Che and Chung examine what I call unilateral expectation damages and where only party A can claim expectation damages if B fails to deliver but B cannot claim damages from A for insufficient investments. To be sure, determining the true level of bilateral expectation damages may be more demanding than that of unilateral damages. But to imagine that the parties have signed a contract which remains silent about investments seems to take the case to the other extreme.

To defend the approach of Che and Chung by making use of the language of contract theory, one might argue that delivery of the product is verifiable in 
front of courts while investments are not. In such an informational setting, unilateral expectation damages may be verifiable while bilateral ones are not. In fact, Che and Chung also investigate liquidated damages where they restrict parties to condition on delivery but not on investments, well in line with the above assumption on verifiability. Yet, by promoting reliance damages, they do not strictly adhere to this assumption because, for reliance damages to work, investments would have to be verifiable as well. In any case, while Che and Chung have provided a very interesting analysis of cooperative investments under some second best constraint the present paper provides the pure theory of such investments.

The paper is organized as follows. Section 2 introduces the model of cooperative investments and it spells out the game induced by bilateral expectation damages and by more general regimes of bilateral compensation. Section 3 solves the game induced by such regimes. The first best can be reached if renegotiations are ruled out as well as if inefficient ex post decisions are expected to be renegotiated. It is this section which establishes that expectation damages perform particularly well in the case of cooperative investments provided, of course, that their bilateral nature is taken into account. The efficiency results follows from the fact that the efficient solution forms a saddle point of both parties' payoff functions. Section 4 compares the findings of the present paper with those of Che and Chung (1999) who examine unilateral expectation damages where the investing party only may claim damages. Section 5 revisits contracting under reliance damages. For binary delivery choice, the first best can be reached. Section 6 concludes.

\section{The Model}

Two parties A and B are involved in a seller-buyer relationship. At stage 1 , party A faces an investment decision $r \in R$. Then, at stage 2 , there is a random move $\omega \in \Omega$ of nature. Party B's delivery choice $y \in Y$ is due at stage 3. Our notation is general enough to cover both cases where the buyer or the seller is the investing party. Moreover, choice sets do not have to be restricted. Decisions could be continuous or discrete and they are even allowed to be more than one-dimensional.

Before any compensation takes place, the net profits of party A and B are 
denoted by $A(r, \omega, y)$ and $B(r, \omega, y)$, referred to as pre-law payoff functions. The social surplus is denoted by $W(r, \omega, y)=A(r, \omega, y)+B(r, \omega, y)$. For given investments $r$ and move $\omega$ of nature, the socially best response is

$$
y^{+}(r, \omega) \in \arg \max _{y \in Y} W(r, \omega, y) .
$$

The efficient investment decision solves

$$
r^{*} \in \arg \max _{r \in R} E\left[W\left(r, \omega, y^{+}(r, \omega)\right)\right] .
$$

It is tacitly assumed that the above optimization problems have solutions. Moreover, the socially best response to efficient investments $y^{*}(\omega)=y^{+}\left(r^{*}, \omega\right)$ is called the efficient delivery choice. Finally, the efficient solution (first best) is reached if A invests efficiently and if B responds with the efficient delivery choice.

Imagine now that the parties have signed contract $[\bar{r}, \bar{y}, T]$ stipulating that A should invest $\bar{r} \in R$, B should choose $\bar{y} \in Y$ in consideration of which the net payment from A to B is $T$. The actual investment decision and delivery choice are denoted by $r$ and $y$, respectively. Then party A may claim damages from B if B has violated the contract $(y \neq \bar{y})$ and if his violating the contract has led to a loss for A, i.e. $A(r, \omega, \bar{y})>A(r, \omega, y)$. For short, A may claim expectation damages from $\mathrm{B}$ amounting to

$$
D_{A}(r, \omega, y)=\max [A(r, \omega, \bar{y})-A(r, \omega, y), 0] .
$$

By the same token, party B may claim expectation damages from A amounting to

$$
D_{B}(r, \omega, y)=\max [B(\bar{r}, \omega, y)-B(r, \omega, y), 0] .
$$

The main focus will be on bilateral expectation damages in the above sense. Yet, in cases of unjustified enrichment or agency of necessity, B may also claim compensation from A if B's deviation $(y \neq \bar{y})$ has lead to a gain for A, i.e. $A(r, \omega, \bar{y})<A(r, \omega, y) .{ }^{3}$ Under full compensation, party A's claim would amount to

$$
D_{A}(r, \omega, y)=A(r, \omega, \bar{y})-A(r, \omega, y)
$$

\footnotetext{
${ }^{3}$ See $\S \S 812$ - 822 BGB (unjustified enrichement) and $\S \S 677$ - 687 BGB (agency of necessity). I am grateful to Hans-Bernd Schäfer who has pointed out the relevance of unjustified enrichment and agency of necessity for the present setting.
} 
and similarly for party B.

Finally, the law may also provide for intermediate cases. If parties A and $\mathrm{B}$ can claim compensation in the ranges

$$
A(r, \omega, \bar{y})-A(r, \omega, y) \leq D_{A}(r, \omega, y) \leq \max [A(r, \omega, \bar{y})-A(r, \omega, y), 0]
$$

and

$$
B(\bar{r}, \omega, y)-B(r, \omega, y) \leq D_{B}(r, \omega, y) \leq \max [B(\bar{r}, \omega, y)-B(r, \omega, y), 0]
$$

then the relationship is governed by a regime of bilateral compensation. The aim of the present paper is to explore the incentives arising from such regimes. Notice, under any regime of bilateral compensation in the above sense,

$$
D_{A}(r, \omega, \bar{y})=0 \text { and } D_{B}(\bar{r}, \omega, y)=0
$$

must hold for all $r, \omega$ and $y$. The post-law payoff functions of A and B under a regime of bilateral compensation are denoted as

$$
\phi(r, \omega, y)=A(r, \omega, y)+D_{A}(r, \omega, y)-D_{B}(r, \omega, y)-T
$$

and $\psi(r, \omega, y)=W(r, \omega, y)-\phi(r, \omega, y)$, respectively.

The focus of the present paper is on cooperative investments. While party A must cover investment costs $g(r)$, cooperative investments do not directly affect her own benefits $H(\omega, y)$ but they directly enter the other party's payoff function. In other words, under cooperative investments, A's payoff function $A(r, \omega, y)=H(\omega, y)-g(r)$ is additively separable in investments.

At the other extreme, investments are called selfish if A's investments do not directly enter B's payoff function, i.e. $B=B(\omega, y)$. Notice, under any regime of bilateral compensation, party $\mathrm{B}$ cannot raise any claims, i.e. $D_{B}(r, \omega, y) \equiv 0$ if investments are of the selfish type. In other words, for selfish investments, there is no difference between unilateral and bilateral compensation.

Much of the earlier literature on the economic analysis of contract law including Che and Chung (1999) deals with continuous and one-dimensional investment decisions $R=[0, \infty)$ combined with binary delivery choice $Y=$ $\left\{y_{L}, y_{H}\right\}$. Edlin and Reichelstein (1996), in contrast, examine continuous 
choice though in a setting of selfish investments. Their model adapted to cooperative investments may also serve as an illustration of the present framework. Party A is facing again a one-dimensional continuous investment decision $r \in R=[0, \infty)$ before party B must decide on a continuous delivery choice $y \in Y \subset[0, \infty)$. The above two examples are referred to as binary and continuous delivery choice, respectively.

\section{The Main Results}

From the economic perspective, efficiency properties of the game with postlaw payoff functions induced by regimes of bilateral compensation are at stake. Desirable properties include that the efficient solution is a subgame perfect equilibrium outcome, all subgame perfect equilibria are payoff equivalent, and, renegotiations off the equilibrium path do not distort incentives. It turns out that all these desirable properties follow from the so-called saddle point property which requires the efficient solution to be a saddle point of the post-law payoff functions. The saddle point property follows from the two conditions

$$
\phi\left(r^{*}, \omega, y^{*}(\omega)\right) \leq \phi\left(r^{*}, \omega, y\right) \text { and } \psi\left(r^{*}, \omega, y^{*}(\omega)\right) \leq \psi\left(r, \omega, y^{*}(\omega)\right)
$$

which must hold for all $r, \omega$ and $y$. In fact, it follows from (5) that

$$
\begin{aligned}
\psi\left(r^{*}, \omega, y\right) & =W\left(r^{*}, \omega, y\right)-\phi\left(r^{*}, \omega, y\right) \leq \\
W\left(r^{*}, \omega, y^{*}(\omega)\right)-\phi\left(r^{*}, \omega, y^{*}(\omega)\right) & =\psi\left(r^{*}, \omega, y^{*}(\omega)\right) \leq \psi\left(r, \omega, y^{*}(\omega)\right)
\end{aligned}
$$

and, similarly, that

$$
E\left[\phi\left(r, \omega, y^{*}(\omega)\right)\right] \leq E\left[\phi\left(r^{*}, \omega, y^{*}(\omega)\right)\right] \leq E\left[\phi\left(r^{*}, \omega, y\right)\right]
$$

must hold for all $r$ and $y$. In this sense, (5) is sufficient to ensure that the efficient solution is a saddle point of B's post-law payoff function and of A's post-law payoff function in expected terms. The following proposition establishes that condition (5) implies the desirable properties of efficiency.

Proposition 1 Suppose the post-law payoff functions satisfy the saddle point property (5). Then the efficient solution emerges under subgame perfect equilibrium. All subgame perfect equilibria are payoff equivalent. This remains to 
be true even if, off the equilibrium path, parties anticipate inefficient delivery choices to be renegotiated.

Proof. Before proving the proposition, two lemmas are established.

Lemma 1 If $y^{B}(r, \omega) \in \arg \max _{y} \psi(r, \omega, y)$ and if $r^{A}$ is such that

$$
E\left[\phi\left(r^{A}, \omega, y^{B}\left(r^{A}, \omega\right)\right)\right] \geq E\left[\phi\left(r^{*}, \omega, y^{B}\left(r^{*}, \omega\right)\right)\right],
$$

then $\left.\left[r^{A}, y^{B}\left(r^{A}, \omega\right)\right)\right]$ is a subgame perfect equilibrium outcome and it holds that

$$
E\left[\phi\left(r^{A}, \omega, y^{B}\left(r^{A}, \omega\right)\right)\right]=E\left[\phi\left(r^{*}, \omega, y^{*}(\omega)\right)\right]
$$

and

$$
E\left[\psi\left(r^{A}, \omega, y^{B}\left(r^{A}, \omega\right)\right)\right]=E\left[\psi\left(r^{*}, \omega, y^{*}(\omega)\right)\right] .
$$

Proof of Lemma 1. It follows from the saddle point property (5) and the assumptions of the lemma that

$$
E\left[\phi\left(r^{A}, \omega, y^{B}\left(r^{A}, \omega\right)\right)\right] \geq E\left[\phi\left(r^{*}, \omega, y^{B}\left(r^{*}, \omega\right)\right)\right] \geq E\left[\phi\left(r^{*}, \omega, y^{*}(\omega)\right)\right]
$$

and

$$
E\left[\psi\left(r^{A}, \omega, y^{B}\left(r^{A}, \omega\right)\right)\right] \geq E\left[\psi\left(r^{A}, \omega, y^{*}(\omega)\right)\right] \geq E\left[\psi\left(r^{*}, \omega, y^{*}(\omega)\right)\right] .
$$

Hence, by summing up,

$$
E\left[W\left(r^{A}, \omega, y^{B}\left(r^{A}, \omega\right)\right)\right] \geq E\left[W\left(r^{*}, \omega, y^{*}(\omega)\right)\right] .
$$

Since the efficient solution maximizes expected surplus, the last inequality must be binding and, hence, the other inequalities must be binding as well. As a consequence, $r^{A}$ must be optimal from A's view and, hence, Lemma 1 is established.

If investments $r$ and state of nature $\omega$ are such that B's best response $y^{B}(r, \omega)$ fails to be a socially best response then renegotiations may lead to a different delivery choice $\hat{y}(r, \omega)$ and to post-renegotiation payoffs $\hat{\phi}(r, \omega)$ and $\hat{\psi}(r, \omega)$ for A and B. Since both parties must agree to renegotiate, the following participation constraints

$$
\hat{\phi}(r, \omega) \geq \phi\left(r, \omega, y^{B}(r, \omega)\right) \text { and } \hat{\psi}(r, \omega) \geq \psi\left(r, \omega, y^{B}(r, \omega)\right)
$$

have to be met. Moreover,

$$
\hat{\phi}(r, \omega)+\hat{\psi}(r, \omega)=W(r, \omega, \hat{y}(r, \omega))
$$

must hold. With this notation, the following lemma can be established. 
Lemma 2 If $y^{B}(r, \omega) \in \arg \max _{y} \psi(r, \omega, y)$ and if $\hat{r}$ is such that

$$
E[\hat{\phi}(\hat{r}, \omega)] \geq E\left[\hat{\phi}\left(r^{*}, \omega\right)\right]
$$

then $\left.\left[\hat{r}, y^{B}(\hat{r}, \omega)\right)\right]$ is a subgame perfect equilibrium outcome and it holds that

$$
E[\hat{\phi}(\hat{r}, \omega)]=E\left[\phi\left(r^{*}, \omega, y^{*}(\omega)\right)\right]
$$

and

$$
E[\hat{\psi}(\hat{r}, \omega)]=E\left[\psi\left(r^{*}, \omega, y^{*}(\omega)\right)\right]
$$

The proof of Lemma 2 follows along similar lines as the one of Lemma 1 and, for that reason, is omitted. By making use of the two lemmas, the proposition can be established as follows. It follows from the saddle point property, that $y^{*}(\omega)$ is a best response of B to $r^{*}$ and $\omega$. Lemma 1 then immediately leads to the conclusion that the efficient solution must be a subgame perfect equilibrium outcome. Lemma 1 also implies that all subgame perfect equilibria must be payoff equivalent.

If, off the equilibrium path, renegotiations take place then it follows from Lemma 2 that $r^{*}$ remains to be a best decision of A. Moreover, if other equilibria exist, they must be payoff equivalent under renegotiations as well as follows from Lemma 2. Proposition 1 is fully established.

Notice, while the existing literature mainly deals with explicit solutions of the renegotiation game such as splitting the renegotiation surplus in fixed shares, the above proposition is more general as it only makes use of the participation constraints. It is not even required that renegotiations always lead to ex post efficient decisions.

As a next step, the saddle point property is expressed in terms of the damage rule in a way which holds for all investment types. The result will then be applied to the more specific cases of cooperative and selfish investments. The proposition holds under the following assumptions. Party A's claims do not depend on actual investments, i.e. $D_{A}=D_{A}(\omega, y)$ and

$$
D_{A}(\omega, y) \geq A\left(r^{*}, \omega, \bar{y}\right)-A\left(r^{*}, \omega, y\right)
$$

holds for all $\omega$ and $y$. Moreover, at efficient delivery choices $y^{*}(\omega),(6)$ is assumed to be binding. Under these assumptions, the following proposition can be established. 
Proposition 2 If the parties have signed a contract stipulating efficient investments (i.e. $\bar{r}=r^{*}$ ) and if the above assumptions are met, then the post-law payoff functions satisfy the saddle point property (5).

Proof. The proof is very elementary. It follows from (6) that

$$
\phi\left(r^{*}, \omega, y\right)=A\left(r^{*}, \omega, y\right)+D_{A}(\omega, y)-T \geq A\left(r^{*}, \omega, \bar{y}\right)-T=\phi\left(r^{*}, \omega, y^{*}(\omega)\right)
$$

and from (4) that

$$
\begin{aligned}
& \psi\left(r, \omega, y^{*}(\omega)\right)=B\left(r, \omega, y^{*}(\omega)\right)+D_{B}\left(r, \omega, y^{*}(\omega)\right)-D_{A}\left(\omega, y^{*}(\omega)\right)+T \\
\geq & B\left(r^{*}, \omega, y^{*}(\omega)\right)+A\left(r^{*}, \omega, y^{*}(\omega)\right)-A\left(r^{*}, \omega, \bar{y}\right)+T=\psi\left(r^{*}, \omega, y^{*}(\omega)\right)
\end{aligned}
$$

must hold for all $r, \omega$ and $y$. The saddle point property is fully established.

The driving force behind the above result is that A's claims are subject to full compensation where compensation must be based on efficient investments even if actual investments were different.

Let us, first, apply the proposition to cooperative investments. In this case,

$$
A(r, \omega, \bar{y})-A(r, \omega, y)=H(\omega, \bar{y})-H(\omega, y)
$$

does not depend on actual investments and, hence, it seems natural if A's claims neither depend on actual investments. Moreover, if the contract specifies a delivery choice $\bar{y}=y_{H}$ such that

$$
H\left(\omega, y^{*}(\omega)\right) \leq H(\omega, \bar{y})
$$

holds for all states $\omega$ then the assumption of the proposition necessarily holds whenever A is granted expectation damages according to (1). In other words, contracts specifying a delivery choice from the proper range combined with expectation damages in the strict sense induce all desirable efficiency properties if investments are of the cooperative type.

Second, in the case of selfish investments, the assumption that A's claims should not depend on actual investments is not in line with legal practice. If expectation damages are granted, they will be based on actual, not on fictitious decisions. In this sense, while formally correct for all types of investments, Proposition 2 is of practical relevance for the case of cooperative investments only. 
If, in the case of selfish investments, party A's claims were based on actual decisions, subject to full compensation (3) then A's post-law payoff would amount to $\phi=\phi(r, \omega)=A(r, \omega, \bar{y})-T$, no matter how B actually decides. Therefore, party B's post-law payoff would be $W(r, \omega, y)-A(r, \omega, \bar{y})+T$ such that B's best response would always coincide with the socially best response. As a consequence, on and off the equilibrium path, there would be no scope for renegotiations. In order to provide efficient incentives to invest, the contract would require fine tuning with respect to the stipulated delivery choice $\bar{y}$. In other words, in the case of selfish investments, either expectation damages must be based on fictitious investments or the contract must be fine tuned with respect to the delivery choice as specified in the contract.

Moreover, still in the case of selfish investments, specifying $\bar{y}$ high enough to have expectation damages (1) resulting in full compensation (3) may be in conflict with the fine tuning required to provide efficient investment incentives. Nevertheless, Edlin and Reichelstein (1996) have shown that, for selfish investments in the continuous delivery choice model, specifying a constant delivery choice may still provide efficient incentives to invest provided that renegotiations to socially best responses can be assumed always to take place. Since the saddle point property no longer holds, their argument is more intricate. In particular, fine tuning would be involved again.

A final remark on bilateral expectation damages in the setting of cooperative investments seems in order. Suppose the contract stipulates a delivery choice such that (7) is violated with positive probability. Then the efficient delivery choice will no longer be B's best response to efficient investments. Yet, if ex post inefficient responses are always renegotiated to the socially best response, fine tuning could again be conjectured to restore full efficiency. To explore the conjecture, let us consider the example of continuous delivery choice with the specifications

$$
H_{y}(\omega, y)>0, B_{y}(r, \omega, y)<0, H_{y y}(\omega, y)+B_{y y}(r, \omega, y)<0
$$

and

$$
B_{r}(r, \omega, y)>0, B_{r y}(r, \omega, y)>0 \text { and } g_{r}(r)>0 .
$$

Suppose the contract stipulates efficient investments $\bar{r}=r^{*}$ but A considers to choose investments from the range $r \leq r^{*}$ instead. Then, as follows from 
$(4)$,

$$
D_{B}(r, \omega, y)=B\left(r^{*}, \omega, y\right)-B(r, \omega, y)
$$

and party B's post-law payoff amounts to

$$
\psi=\psi(\omega, y)= \begin{cases}B\left(r^{*}, \omega, y\right)+H(\omega, y)-H(\omega, \bar{y})+T & \text { if } y \leq \bar{y} \\ B\left(r^{*}, \omega, y\right)+T & \text { if } \bar{y} \leq y\end{cases}
$$

and, hence, B's best response is

$$
y^{B}=y^{B}(\omega)=\left\{\begin{array}{lll}
y^{*}(\omega) & \text { if } y^{*}(\omega) \leq \bar{y} \\
\bar{y} & \text { if } \bar{y} \leq y^{*}(\omega)
\end{array}\right.
$$

as follows from the concavity of social surplus with respect to delivery choice. Under B's best response and without renegotiations, A's payoff amounts to

$$
\phi\left(r, \omega, y^{B}(\omega)\right)=B\left(r, \omega, y^{B}(\omega)\right)-B\left(r^{*}, \omega, y^{B}(\omega)\right)+H(\omega, \bar{y})-g(r)-T .
$$

If ex post inefficient responses are renegotiated to a socially best response and if A obtains a fixed share $\alpha$ of the renegotiation surplus then A's payoff with renegotiations amounts to

$$
\begin{aligned}
\hat{\phi}(r, \omega)= & W\left(r, \omega, y^{+}(r, \omega)\right)+\gamma(\omega)+ \\
& (1-\alpha)\left[W\left(r, \omega, y^{B}(\omega)\right)-W\left(r, \omega, y^{+}(r, \omega)\right)\right]
\end{aligned}
$$

where $\gamma(\omega)$ collects terms that do not depend on actual investments $r$. It follows that the derivative from the left at $r^{*}$

$$
\frac{d}{d r} E\left[\hat{\phi}\left(r^{*}, \omega\right)\right]=(1-\alpha) E\left[B_{r}\left(r^{*}, \omega, y^{B}(\omega)\right)-B_{r}\left(r^{*}, \omega, y^{*}(\omega)\right)\right]<0
$$

must be negative. To summarize the findings, recall that cooperative investments in a model of continuous delivery choice are at stake. By assumption, the contract specifies a delivery choice such that (7) is violated with positive probability. Then, even if ex post inefficient responses are costlessly renegotiated to a socially best response, incentives to invest are distorted downwards.

The main conclusion of the present section is that, under the regime of bilateral expectation damages and with contracts that specify a delivery choice in the range (7), the investing party in a setting of cooperative investments has efficient incentives, no matter whether inefficient delivery choices are renegotiated or not. These findings are in contrast to those of Che and Chung (1999). The next section examines the differences. 


\section{Unilateral Expectation Damages}

Che and Chung (1999) investigate the case of unilateral expectation damages where only the investing party can claim expectation damages. While Che and Chung have dealt with binary delivery choice, there analysis can be generalized as follows. Party B's post-law payoff function under a regime of unilateral expectation damages is

$$
\psi^{u}(r, \omega, y)=B(r, \omega, y)+T-\max [H(\omega, \bar{y})-H(\omega, y), 0] .
$$

For simplicity, let us assume that there exist delivery choices $y_{L}, y_{H} \in Y$ such that

$$
H(\omega, y) \leq H\left(\omega, y_{H}\right)
$$

and

$$
H\left(\omega, y_{L}\right) \leq H(\omega, y) \text { and } B(r, \omega, y) \leq B\left(r, \omega, y_{L}\right)
$$

hold for all states of nature and all investment levels. Moreover, let us assume that investments are one-dimensional $R \subset[0, \infty)$ such that $g(r)$ is strictly increasing while $B(r, \omega, y)$ is at least weakly increasing in $r$ to capture the cooperative nature of investments. Think of a continuous delivery choice setting with a compact choice set $Y$. If party $\mathrm{A}$ is the buyer then take $y_{L}$ and $y_{H}$ as the minimum and maximum quantity, respectively. Similarly, if party is the seller then the maximum and minimum quantity could serve as $y_{L}$ and $y_{H}$, respectively.

Proposition 3 Suppose the initial contract specifies delivery choice $\bar{y}=y_{H}$. Then, under the regime of unilateral expectation damages, party B's delivery choice is the socially best response $y^{+}(r, \omega)$. But party $A$ has no incentive to invest, that is A simply minimizes costs

$$
r=r^{0} \in \arg \min _{r \in R} g(r) .
$$

Proof. If delivery choice $\bar{y}=y_{H}$ has been specified then party B's post-law payoff amounts to

$$
\psi^{u}(r, \omega, y)=B(r, \omega, y)+H(\omega, y)+T-H\left(\omega, y_{H}\right) .
$$

Hence $\mathrm{B}$ has the incentive to choose the socially best response $y^{+}(r, \omega)$. Therefore, party A's post-law payoff amounts to

$$
\phi^{u}(r, \omega)=H\left(\omega, y_{H}\right)-T-g(r)
$$


from which it follows immediately that A has no incentives to invest.

Notice, under bilateral expectation damages, contracts specifying delivery choice $y_{H}$ provide first best incentives to invest while, under unilateral expectation damages, they provide no incentives at all.

At the other extreme, the case of contracts is considered which stipulate delivery choice $y_{L}$. Under bilateral expectation damages, such contracts would perform worse than those which specify $y_{H}$ as has been shown by the example at the end of the previous section. Under unilateral expectation damages, however, the converse is true as the following proposition shows.

Proposition 4 Suppose the initial contract specifies delivery choice $\bar{y}=y_{L}$. If parties anticipate inefficient delivery choices to be renegotiated then, under unilateral expectation damages, party $A$ has incentives to invest according to

$$
r^{u} \in \arg \max \alpha E\left[W\left(r, \omega, y^{+}(r, \omega)\right)\right]-\beta g(r)-E\left[\alpha B\left(r, \omega, y_{L}\right)\right] .
$$

It holds that $0 \leq r^{u} \leq r^{*}$ where, typically, both inequalities are strict.

Proof. If delivery choice $\bar{y}=y_{L}$ has been specified then party B's post-law payoff amounts to

$$
\psi^{u}(r, \omega, y)=B(r, \omega, y)+T
$$

Since, by assumption,

$$
y_{L} \in \arg \max _{y \in Y} B(r, \omega, y)
$$

it follows that $\mathrm{B}$ chooses $y_{L}$ if renegotiations would brake down. If they do not and if A obtains a fixed share $\alpha$ of the renegotiation surplus, then party A's post-renegotiation payoff amounts to

$$
\begin{aligned}
\hat{\phi}(r, \omega)= & H\left(\omega, y_{L}\right)-g(r)-T+ \\
& \alpha\left[W\left(r, \omega, y^{+}(r, \omega)\right)-W\left(r, \omega, y_{L}\right)\right] \\
= & \beta H\left(\omega, y_{L}\right)-\beta g(r)-T+ \\
& \alpha W\left(r, \omega, y^{+}(r, \omega)\right)-\alpha B\left(r, \omega, y_{L}\right)
\end{aligned}
$$

from which (10) follows immediately.

The first term in (10) attains its maximum at efficient investments $r^{*}$. The second and third term, by assumption, are strictly decreasing in $r$. It follows that $0 \leq r^{u} \leq r^{*}$ must hold indeed. In a differentiable setting, the 
inequality would be strict because the derivative of the first term vanishes at $r^{*}$ whereas the second and third term would have a negative derivative at $r^{*}$. Similarly, under mild assumptions, it must hold that $r^{u}>0$. The proposition is established.

In the binary choice setting of Che and Chung [1999], the only two possibilities are to specify either $\bar{y}=y_{L}$ or $\bar{y}=y_{H}$ in the contract. Under unilateral expectation damages, specifying $\bar{y}=y_{L}$ outperforms specifying $\bar{y}=y_{H}$. Renegotiations are needed to ensure efficient delivery choice. Nevertheless, incentives to invest remain suboptimal.

Under bilateral expectation damages or, more generally, under any regime of bilateral compensation, specifying $\bar{y}=y_{H}$ does not only outperform specifying $\bar{y}=y_{L}$ but it even induces efficient investments and efficient delivery choice, no matter whether, off the equilibrium path, renegotiations take place or can be ruled out.

\section{Reliance Damages}

In the introduction, I have argued why party A would claim expectation damages and would not opt for reliance damages. Nevertheless, it might be worthwhile to explore incentives if only reliance damages were granted. In the case of cooperative investments, reliance damages of this kind have the potential to provide efficient incentives to invest, well in line with the earlier findings of Che and Chung (1999).

Reliance damages are typically confined to binary delivery choice. So let us assume that $Y=\left\{y_{L}, y_{H}\right\}$ and that assumptions (8) and (9) are met. It will even be required that, at delivery choice $y_{L}$, party B's pre-law payoff is not affected by party A's investment decision, i.e.

$$
B\left(r, \omega, y_{L}\right)=B\left(\omega, y_{L}\right)
$$

holds for all $r$. If party $\mathrm{B}$ is the seller in a setting of quantity choice, this assumption would naturally hold: at zero production, the cost structure of B does not matter.

Finally, well in line with the nature of cooperative investments, it is assumed that $g(r)$ is a strictly, $B(r, \omega, y)$ at least a weakly increasing function of investments $r \in R \subset[0, \infty)$. 
Under reliance damages, contracts would specify a price $T$ which becomes due in case of performance $y=y_{H}$. Furthermore, to reflect ex ante bargaining power, parties may agree to a lump-sum payment $t$. Taking reliance damages into account, net payments from A to B amount to

$$
\tau(r, y)=\left\{\begin{array}{ccc}
T-t & \text { if } \quad y=y_{H} \\
-g(r)-t & \text { if } \quad y=y_{L}
\end{array} .\right.
$$

Given the above contract, B's payoff amounts to

$$
\psi(r, \omega, y)=B(r, \omega, y)+\tau(r, y)
$$

The following proposition can be established.

Proposition 5 Suppose reliance damages only are granted and parties anticipate inefficient delivery choices to be renegotiated. Then party A's incentives to invest $r(T)$ just depend on the price $T$. Moreover, there exist prices $T_{L}$ and $T_{H}$ which provide insufficient and excessive incentives to invest, respectively, i.e.

$$
r\left(T_{L}\right) \leq r^{*} \leq r\left(T_{H}\right)
$$

Hence, if $r(T)$ is a continuous function of the price then there exists a price $T^{*}$ under which the efficient solution emerges, i.e.

$$
r\left(T^{*}\right)=r^{*}
$$

Proof. Let

$$
y^{B}=y^{B}(r, \omega, T) \in \arg \max _{y \in Y} B(r, \omega, y)+\tau(r, y)
$$

denote B's delivery choice in case renegotiations would break down. It follows that

$$
y^{B}(r, \omega, T)=\left\{\begin{array}{lll}
y_{H} & \text { if } & T+B\left(r, \omega, y_{H}\right)+g(r)>B\left(\omega, y_{L}\right) \\
y_{L} & \text { if } \quad T+B\left(r, \omega, y_{H}\right)+g(r)<B\left(\omega, y_{L}\right)
\end{array} .\right.
$$

Since $B\left(r, \omega, y_{H}\right)+g(r)$ is strictly increasing in $r$, there exists a cut-off value $\bar{r}(\omega, T)$ such that $y^{B}(r, \omega, T)=y_{H}$ iff $r>\bar{r}(\omega, T)$.

But renegotiations do not break down if $y^{B}$ fails to be the socially best response. If party A obtains a fixed share $\alpha$ of the renegotiation surplus, her 
payoff amounts to

$$
\begin{aligned}
\hat{\phi}(r, \omega, T)= & H\left(\omega, y^{B}(r, \omega, T)\right)-g(r)-\tau\left(r, y^{B}(r, \omega, T)\right)+ \\
& \alpha\left[W\left(r, \omega, y^{+}(r, \omega)\right)-W\left(r, \omega, y^{B}(r, \omega, T)\right)\right] \\
= & \beta H\left(\omega, y^{B}(r, \omega, T)\right)-\beta g(r)-\alpha B\left(r, \omega, y^{B}(r, \omega, T)\right)- \\
& \tau\left(r, y^{B}(r, \omega, T)\right)+\alpha W\left(r, \omega, y^{+}(r, \omega)\right) .
\end{aligned}
$$

If we write, for short, $\hat{\phi}(r, \omega, T)=t+\alpha W\left(r, \omega, y^{+}(r, \omega)\right)+M(r, \omega, T)$ then it holds that

$$
M(r, \omega, T)=\left\{\begin{array}{ccc}
\beta H\left(\omega, y_{H}\right)-T-\alpha B\left(r, \omega, y_{H}\right)-\beta g(r) & \text { if } & \bar{r}(\omega, T)<r \\
\beta H\left(\omega, y_{L}\right)-\alpha B\left(\omega, y_{L}\right)+\alpha g(r) & \text { if } \quad r<\bar{r}(\omega, T)
\end{array} .\right.
$$

Notice, the function of the second line is strictly increasing whereas the function of the first line is strictly decreasing in $r$.

Moreover, given the above contract, the incentives to invest

$$
r=r(T) \in \arg \max E[\hat{\phi}(r, \omega, T)]
$$

just depend on the price $T$ due in case of delivery.

Choose $T_{L}$ such that

$$
T_{L}+B\left(r^{*}, \omega, y_{H}\right)+g\left(r^{*}\right)>B\left(\omega, y_{L}\right)
$$

and $T_{H}$ such that

$$
T_{H}+B\left(r^{*}, \omega, y_{H}\right)+g\left(r^{*}\right)<B\left(\omega, y_{L}\right)
$$

hold for all $\omega$. It then follows that $\bar{r}\left(\omega, T_{L}\right)<r^{*}$ and $r^{*}<\bar{r}\left(\omega, T_{H}\right)$ for all $\omega$. Therefore the function $E\left[M\left(r, \omega, T_{L}\right)\right]$ is strictly decreasing in the range $\left[r^{*}, \infty\right)$ and the function $E\left[M\left(r, \omega, T_{H}\right)\right]$ is strictly increasing in the range $\left[0, r^{*}\right]$. Since $\alpha E\left[W\left(r, \omega, y^{+}(r, \omega)\right)\right]$ attains its maximum at $r^{*}$, it follows that $r\left(T_{L}\right) \leq r^{*} \leq r\left(T_{H}\right)$ must hold.

The continuity of $r(T)$ as a function of $T$ would follow from the concavity of $E[\hat{\phi}(r, \omega, T)]$ as a function of $r$. If such is the case then, as the above proposition shows, the contract specifying the appropriate price $T^{*}$ leads to the efficient solution provided that reliance damages are granted to A. For such a scheme to work, investment levels must be verifiable. Yet, if they are then bilateral expectation damages could also be enforced. Since bilateral expectation damages lead to efficient solutions more generally, the results of the present paper rehabilitate expectation damages for relationship-specific investments of the cooperative type. 


\section{Concluding Remarks}

The economic analysis of contract law has examined incentives for investments under various breach remedies. No doubt, for legal practice, the most prevalent measure is expectation damages. The early literature concentrates on selfish investments which directly benefit the investing party. If the performance decision is binary and if investments are selfish then expectation damages lead to overreliance (Shavell (1980) and Rogerson (1984)). For selfish investments, the first best is induced by expectation damages only if the performance decision is a continuous delivery choice and if inefficient delivery choices are renegotiated to the ex post efficient decision (Edlin and Reichelstein (1996)). Recall, if investments are of the selfish type, fine tuning is required to specify a delivery choice that does not distort incentives to invest.

The present paper revisits cooperative investments as first studied by Che and Chung (1999). It argues that, in the case of cooperative investments, expectation damages are of a bilateral nature and, as a consequence, that a strict interpretation of legal provisions gives rise to the rule of bilateral expectation damages. If the contract specifies a delivery choice high enough such that A's claims are always subject to full compensation then bilateral expectation damages are shown to provide efficient incentives to invest, no matter whether renegotiations are ruled out or not and no matter whether the performance decision is binary or not.

If Che and Chung attribute poor performance to expectation damages in the case of cooperative investments their findings rest on the assumption that only the investing party may claim damages for breach of contract. Under such a rule, indeed, unilateral expectation damages lead to insufficient investments and other breach remedies may perform better. Therefore, the present paper promotes the idea that Che and Chung's pessimistic view does not follow from a basic defect of expectation damages but rather from neglecting the bilateral nature which expectation damages naturally feature in the case of cooperative investments. 


\section{$7 \quad$ References}

Che, Y.-K. and T.-Y. Chung (1999), "Contract damages and cooperative investments," RAND Journal of Economics (30), 84-105.

Edlin, A. and S. Reichelstein (1996), "Holdups, standard breach remedies, and optimal investments," American Economic Review (86), 478-501.

Rogerson, W.P. (1984), "Efficient reliance and damage measures for breach of contract," RAND Journal of Economics (15), 39-53.

Shavell, S. (1980), "Damage Measures for Breach of Contract", Bell Journal of Economics, 11, 466 - 490. 